\title{
Oxygen desaturation during the six-minute walk test in COPD patients*
}

Análise da dessaturação de oxigênio durante o teste de caminhada de seis minutos em pacientes com DPOC

\author{
Maria Ângela Fontoura Moreira, Gabriel Arriola de Medeiros, \\ Francesco Pinto Boeno, Paulo Roberto Stefani Sanches, \\ Danton Pereira da Silva Júnior, André Frotta Müller
}

\begin{abstract}
Objective: To evaluate the behavior of oxygen saturation curves throughout the six-minute walk test (6MWT) in patients with COPD. Methods: We included 85 patients, all of whom underwent spirometry and were classified as having moderate COPD (modCOPD, $n=30$ ) or severe COPD (sevCOPD, $n=55$ ). All of the patients performed a 6MWT, in a 27-m corridor with continuous $\mathrm{SpO}_{2}$ and $\mathrm{HR}$ monitoring by telemetry. We studied the $\mathrm{SpO}_{2}$ curves in order to determine the time to a 4\% decrease in $\mathrm{SpO}_{2}$, the time to the minimum $\mathrm{SpO}_{2}$ (Tmin), and the post-6MWT time to return to the initial $\mathrm{SpO}_{2}$, the last designated recovery time (RT). For each of those curves, we calculated the slope. Results: The mean age in the modCOPD and sevCOPD groups was $66 \pm 10$ years and $62 \pm 11$ years, respectively. At baseline, $\mathrm{SpO}_{2}$ was $>94 \%$ in all of the patients; none received supplemental oxygen during the 6MWT; and none of the tests were interrupted. The six-minute walk distance did not differ significantly between the groups. The $\mathrm{SpO}_{2}$ values were lowest in the sevCOPD group. There was no difference between the groups regarding RT. In 71\% and 63\% of the sevCOPD and modCOPD group patients, respectively, a $\geq 4 \%$ decrease in $\mathrm{SpO}_{2}$ occurred within the first minute. We found that $\mathrm{FEV}_{1} \%$ correlated significantly with the $\Delta \mathrm{SpO}_{2}(\mathrm{r}=-0.398 ; \mathrm{p}<0.001)$, Tmin $(\mathrm{r}=-0.449 ; \mathrm{p}<0.001)$, and minimum $\mathrm{SpO}_{2}(\mathrm{r}=0.356 ; \mathrm{p}<0.005)$. Conclusions: In the sevCOPD group, in comparison with the modCOPD group, $\mathrm{SpO}_{2}$ was lower and the Tmin was greater, suggesting a worse prognosis in the former.
\end{abstract}

Keywords: Pulmonary disease, chronic obstructive; Exercise test; Blood gas monitoring, transcutaneous.

\section{Resumo}

Objetivo: Avaliar o comportamento da curva de saturação de oxigênio durante o teste de caminhada de seis minutos (TC6) em pacientes com DPOC. Métodos: Incluímos 85 pacientes e todos realizaram espirometria, sendo classificados como portadores de DPOC moderada (DPOCm, $n=30$ ) ou grave (DPOCg, $n=55$ ). Todos os pacientes realizaram TC6 em um corredor de $27 \mathrm{~m}$ com monitoramento contínuo da $\mathrm{SpO}_{2}$ e FC por telemetria. A partir das curvas de $\mathrm{SpO}_{2}$, foram analisados os tempos para atingir a queda de $4 \%$ da $\mathrm{SpO}_{2}$, para atingir a $\mathrm{SpO}_{2}$ mínima (Tmin) e para a recuperação da $\mathrm{SpO}_{2}$ após o TC6 (TR). Foram calculadas as inclinações dessas curvas. Resultados: A média de idade nos grupos DPOCm e DPOCg foi de $62 \pm 11$ anos e $66 \pm 10$ anos, respectivamente. Todos os pacientes iniciaram o teste com $\mathrm{SpO}_{2}>94 \%$, nenhum recebeu suplementação de oxigênio durante o TC6, e não houve interrupções. A distância percorrida no TC6 não apresentou diferença significativa entre os grupos. Os menores valores da $\mathrm{SpO}_{2}$ ocorreram no grupo DPOCg. Não houve diferença no TR entre os grupos, e 71\% e 63\% dos pacientes nos grupos DPOCg e DPOCm, respectivamente, apresentaram queda de $\mathrm{SpO}_{2} \geq$ $4 \%$ até o primeiro minuto. $0 \mathrm{VEF}_{1} \%$ apresentou correlações significativas com $\Delta \mathrm{SpO}_{2}(r=-0,398 ; p<0,001)$, Tmin $(r=-0,449 ; p<0,001)$ e $\mathrm{SpO}_{2}$ mínima $(r=0,356 ; p<0,005)$. Conclusões: As curvas dos pacientes do grupo DPOCg em relação às do grupo DPOCm apresentaram valores menores de $\mathrm{SpO}_{2}$ e maior Tmin, sugerindo um pior prognóstico nos primeiros.

Descritores: Doença pulmonar obstrutiva crônica; Teste de esforço; Monitorização transcutânea dos gases sanguíneos.

\footnotetext{
*Study carried out in the Pulmonary Physiology Clinic, Department of Pulmonology, Porto Alegre Hospital de Clínicas, Porto Alegre, Brazil.

Correspondence to: Maria Ângela Fontoura Moreira. Avenida Neusa Goulart Brizola, 550/605, Petrópolis, CEP 90460-230, Porto Alegre, RS, Brasil.

Tel. 5551 3359-8198. E-mail: maanmo@terra.com.br

Financial support: None.

Submitted: 21 October 2013. Accepted, after review: 5 April 2014.
} 


\section{Introduction}

Advances in research on and in the treatment and diagnosis of lung diseases have shown the importance of including the six-minute walk test (6MWT) in the functional assessment of lung disease patients, more specifically in the detection of exercise-induced hypoxemia, which is considered an important marker of respiratory disease severity. The acquisition of reproducible measurements is necessary for this assessment. ${ }^{(1-5)}$

The 6MWT is widely requested since, in addition to being easy to administer, inexpensive, and well-tolerated by the patient, it is the mode of submaximal exercise that most closely approximates activities of daily living. It is attractive because it combines ease of performance and operational simplicity. Therefore, it is usually used as an adjunctive tool in the assessment of COPD, cystic fibrosis, heart disease, peripheral vascular disease, etc. ${ }^{(2-4,6)}$

The American Thoracic Society guidelines recommend that the 6MWT be performed indoors, along a flat, straight, 30-m track, on which the patient should walk for six minutes, with the aim of covering the greatest distance possible. ${ }^{(7)}$

The 6MWT is among the most commonly used tests to assess exercise tolerance in individuals with chronic obstructive disease and individuals with interstitial disease. Such patients may experience a significant decrease in $\mathrm{SpO}_{2}$ during submaximal exercise or even desaturation at rest. Exertional hypoxemia can be explained by pathophysiological factors, such as airflow limitation, imbalance between oxygen supply and consumption, systemic inflammation, and oxidative stress, affecting peripheral muscle oxygenation. The significant decrease in the levels of circulating oxygen, resulting from the increased demand caused by the effort put forth, can lead to increased blood pressure, increased dyspnea, and increased muscle fatigue, thereby reducing submaximal exercise tolerance. ${ }^{(8)}$

Patients with COPD do not show the same limitation during exercise or activities of daily living. Exercise performance and exercise maintenance depend primarily on flawless interaction among the systems that control ventilation, gas exchange, blood flow, hemoglobin, oxygen/carbon dioxide transport, oxygen use, and carbon dioxide production. ${ }^{(8)}$

In patients with COPD, one of the most important adverse events during the 6MWT is oxygen desaturation, which can be more accurately assessed if there is continuous monitoring throughout the test. Therefore, the objective of the present study was to evaluate the behavior of oxygen saturation curves throughout the 6MWT in patients with COPD.

\section{Methods}

The data were collected between January and December of 2012 in the Pulmonary Physiology Clinic of the Department of Pulmonology of the Hospital de Clínicas de Porto Alegre (HCPA, Porto Alegre Hospital de Clínicas), located in the city of Porto Alegre, Brazil. This study was analyzed and approved by the HCPA Health Research Ethics Committee (Project no. 09-549), and the patients invited to participate in the study gave written informed consent before performing the 6MWT.

We included male and female patients who had been diagnosed with COPD, ${ }^{(9)}$ were stable, and had spirometry results indicative of moderate COPD (modCOPD) or severe COPD (sevCOPD), as classified by the 2002 Brazilian Thoracic Association Guidelines for Pulmonary Function Tests. ${ }^{(10)}$ Spirometry was performed by spirometry technicians certified by the Brazilian Thoracic Association. A spirometer (Jaeger, Würtzburg, Germany) was used, and the predicted values of Crapo were employed. ${ }^{(11)}$ Spirometry was performed $1 \mathrm{~h}$ before the 6MWT on the same day. Values of $\mathrm{FEV}_{1}$ and $\mathrm{VC}$ were obtained from the flowvolume curves.

The 6MWT was conducted in a 27-m corridor in accordance with the America Thoracic Society guidelines. ${ }^{(7)}$ At the HCPA, it is possible to monitor $\mathrm{HR}$ and $\mathrm{SpO}_{2}$ continuously by telemetry throughout the 6MWD with the use of a digital oximetry module and of a software program developed by the Biomedical Engineering team at HCPA. This system allows the simultaneous transfer of $\mathrm{HR}$ and $\mathrm{SpO}_{2}$ data to the computer, making it possible to monitor the degree of oxygen desaturation in real time, which thereby allows a better assessment of the degree of disease severity. ${ }^{(5,7)}$ Figure 1 shows a recorded curve. All of the included patients completed the 6MWT without interruption and had a baseline $\mathrm{SpO}_{2}>94 \%$. None of the patients received supplemental oxygen during the test. We excluded from the sample those with orthopedic impairments, interstitial diseases, or pulmonary arterial hypertension, or with any condition that would compromise 
their ability to perform the 6MWT. The curves showing a $\geq 4 \%$ decrease in $\mathrm{SpO}_{2}$ were analyzed.

We studied the $\mathrm{SpO}_{2}$ curves in order to determine the time to a $4 \%$ decrease in $\mathrm{SpO}_{2}$ and the time to the minimum $\mathrm{SpO}_{2}$, as well as the post-6MWT time to return to the initial $\mathrm{SpO}_{2}$, designated recovery time. We calculated the slope of each of those curves with the following formula: (final $\mathrm{SpO}_{2}-$ initial $\mathrm{SpO}_{2}$ ) $\div$ $\Delta$ time between those points

The slopes were compared to determine changes in them because of the severity of airway obstruction. Figure 2 shows an example of the slopes calculated.

The statistical analysis of the collected data was performed with the Statistical Package for the Social Sciences, version 18.0 (SPSS Inc., Chicago, IL, USA). Data were analyzed for normality and homogeneity of variance. The independent sample t-test was used for the comparison between the two groups. Pearson's correlation test was used for analysis of correlations. For all analyses, the level of significance was set at $p<0.05$. Values are expressed as means and standard deviations.

\section{Results}

The study sample consisted of 85 patients: 55 with sevCOPD (mean age of $62 \pm 11.3$ years and mean body mass index [BMI] of $22.5 \pm 3.3$ $\mathrm{kg} / \mathrm{m}^{2}$ ); and 30 with modCOPD (mean age of $66.0 \pm 10.1$ years and BMl of $25.1 \pm 2.8 \mathrm{~kg} /$ $\mathrm{m}^{2}$ ). Table 1 shows the variables assessed in the two groups.

The groups were found to be homogeneous with respect to age and pre-6MWT $\mathrm{SpO}_{2}$. In neither of the groups did the BMl exceed 30 $\mathrm{kg} / \mathrm{m}^{2}$, a value above which spirometry results are affected. ${ }^{\left({ }^{10)}\right)}$ The six-minute walk distance did not differ significantly between the groups. The minimum $\mathrm{SpO}_{2}$ was significantly lower in the sevCOPD group ( $p<0.014)$. A 4\% decrease in $\mathrm{SpO}_{2}$ occurred within the first minute in $63 \%$ and $71 \%$ of the modCOPD and sevCOPD group patients, respectively. The time to desaturation of $4 \%$ and the recovery time did not differ significantly between the groups; however, the time to the minimum $\mathrm{SpO}_{2}$ was greater in the sevCOPD group than in the modCOPD group $(p<0.001)$. The slopes of the $\mathrm{SpO}_{2}$ curves for

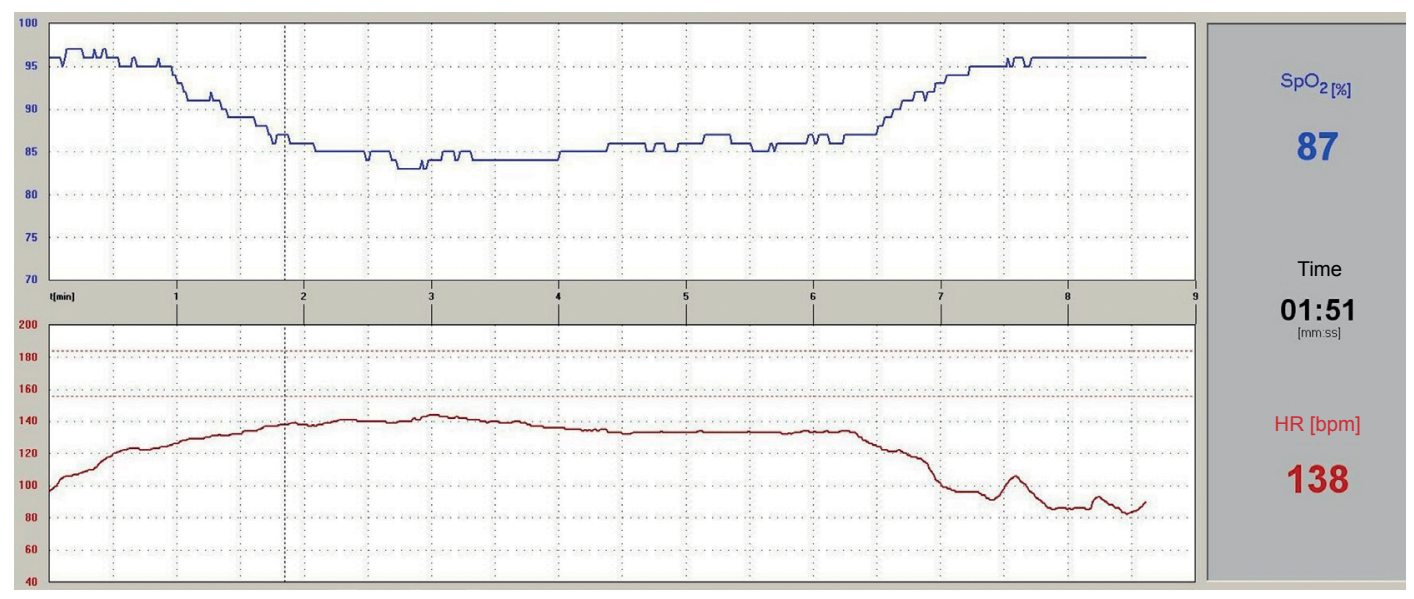

Figure 1 - Monitoring of $\mathrm{HR}$ and $\mathrm{SpO}_{2}$.

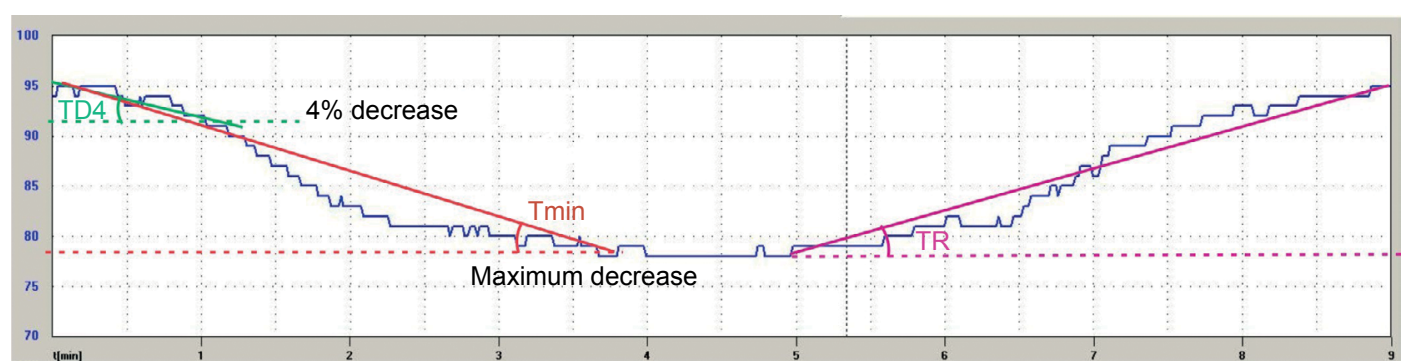

Figure 2 - Example of slopes of the curves. TD4: time to desaturation of 4\%. Tmin: time to the minimum $\mathrm{SpO}_{2}$; and RT: recovery time (i.e., time to return to the initial $\mathrm{SpO} 2$ ). 
Table 1 - General characteristics of the study population.

\begin{tabular}{lccc}
\hline \multicolumn{1}{c}{ Variable } & modCOPD & sevCOPD & $\mathrm{p}$ \\
\cline { 2 - 3 } & $(\mathrm{n}=30)$ & $(\mathrm{n}=55)$ & \\
\hline BMl, kg/m & $25.1 \pm 2.8$ & $22.5 \pm 3.3$ & $0.01^{*}$ \\
Age, years & $66 \pm 10$ & $62 \pm 11$ & 0.11 \\
Pre-6MWT Sp0, $\%$ & $95.0 \pm 1.9$ & $95.0 \pm 2.1$ & 0.85 \\
Minimum $\mathrm{SpO}_{2}, \%$ & $87.3 \pm 3.4$ & $85.0 \pm 4.3$ & $0.01^{*}$ \\
$\mathrm{TD} 4, \mathrm{~s}$ & $64 \pm 36$ & $66 \pm 41$ & 0.81 \\
$\mathrm{Tmin}, \mathrm{s}$ & $109 \pm 55$ & $168 \pm 67$ & $0.01^{*}$ \\
$\mathrm{RT}, \mathrm{s}$ & $112.6 \pm 28.8$ & $120.2 \pm 31.5$ & 0.28 \\
$\mathrm{FEV}_{1} \%$ & $53.1 \pm 9.6$ & $28.0 \pm 6.2$ & $0.01^{*}$ \\
6MWD, $\mathrm{m}$ & $451 \pm 73$ & $435 \pm 74$ & 0.35 \\
Slope of the line for a $\geq 4 \%$ decrease in $\mathrm{SpO}_{2}$ & $0.08 \pm 0.04$ & $0.08 \pm 0.04$ & 0.89 \\
Slope of the line for maximum decrease in $\mathrm{SpO}_{2}$ & $0.08 \pm 0.03$ & $0.07 \pm 0.05$ & 0.27 \\
Slope of the line for return to the initial $\mathrm{SpO}_{2}$ & $0.07 \pm 0.02$ & $0.09 \pm 0.04$ & 0.05 \\
\hline
\end{tabular}

modCOPD: moderate COPD; sevCOPD: severe COPD; BMI: body mass index; 6MWT: six-minute walk test; TD4: time to desaturation of $\geq 4 \%$; $\mathrm{Tmin}$ : time to the minimum $\mathrm{SpO}_{2}$; RT: recovery time (i.e., time to return to the initial $\mathrm{SpO}_{2}$ ); and 6MWD: six-minute walk distance.

desaturation of $4 \%$, maximum decrease, and recovery were not found to differ significantly between the groups. The change in $\mathrm{SpO}_{2}\left(\Delta \mathrm{SpO}_{2}\right)$ between the baseline value and the maximum decrease was statistically different between the two groups $(p=0.005)$.

We found that $\mathrm{FEV}_{1} \%$ showed a moderate positive correlation with the minimum $\mathrm{SpO}_{2}(\mathrm{r}=$ $0.356 ; p<0.005)$, a moderate negative correlation with the $\Delta \mathrm{SpO}_{2}(r=-0.398 ; \mathrm{p}<0.001)$, and a moderate negative correlation with the time to the minimum $\mathrm{SpO}_{2}(r=-0.449 ; \mathrm{p}<0.001)$.

The slope of the maximum decrease in $\mathrm{SpO}_{2}$ showed a moderate negative correlation with the time to the minimum $\mathrm{SpO}_{2}(r=-0,467 ; p<$ $0,001)$, time to desaturation of $4 \%(r=-0.437$; $\mathrm{p}<0.001)$, and minimum $\mathrm{SpO}_{2}(r=-0.393 ; \mathrm{p}$ $<0.001)$. The six-minute walk distance (6MWD) showed no significant correlations with $\mathrm{SpO}_{2}$ or its variations or with $\mathrm{FEV}_{1} \%$.

\section{Discussion}

Exercise-induced desaturation can be measured in the 6MWT and is an index that has prognostic value in interstitial diseases and COPD. $A \geq 4 \%$ decrease in $\mathrm{SpO}_{2}$ suggests significant desaturation and is used for assessing the need for oxygen supplementation in patients with chronic lung disease. ${ }^{(12)}$ Another index of functional capacity is the $6 \mathrm{MWD}$, which has prognostic value in COPD. ${ }^{(13)}$

However, hypoxemia is a major problem in respiratory medicine, since it is very common in
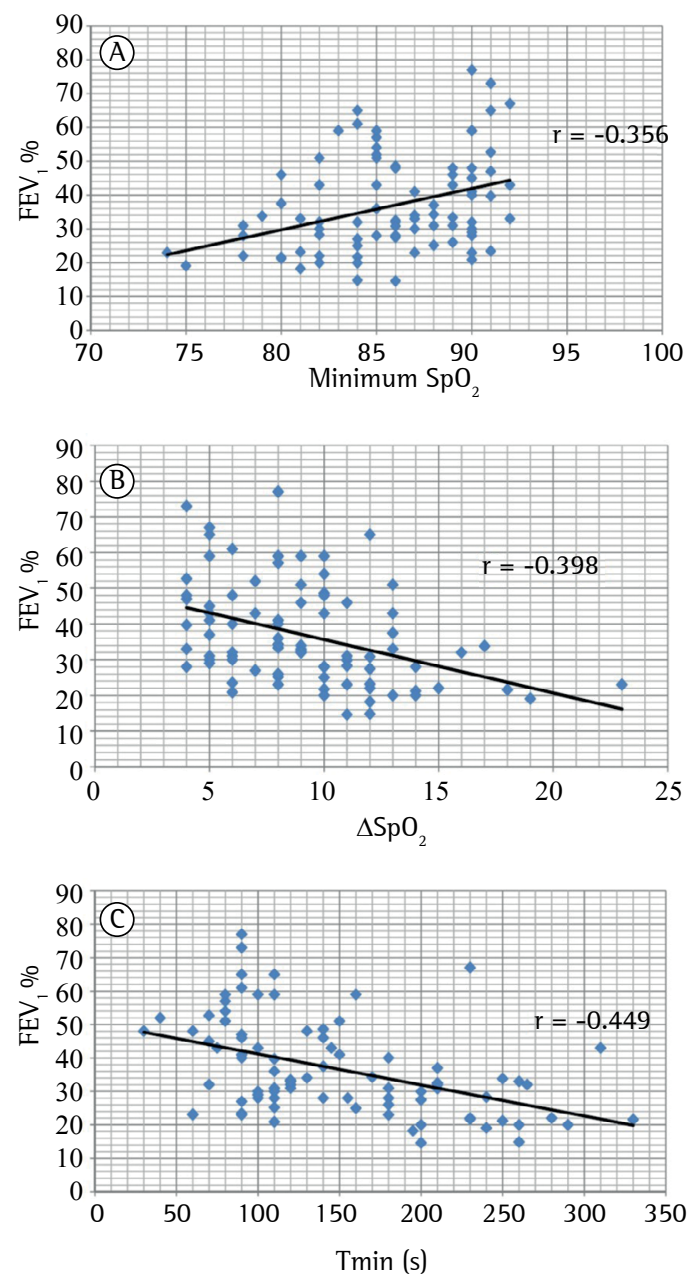

Figure 3 - Correlations of changes in $\mathrm{FEV}_{1} \%$ with the minimum $\mathrm{SpO}_{2}$ (in A), $\Delta \mathrm{SpO}_{2}$ (in B), and time to the minimum $\mathrm{SpO}_{2}$ (Tmin; in $\left.\mathrm{C}\right)$. 
patients with lung disease and must be rapidly assessed and treated to prevent irreversible organ damage.

Exercise-induced desaturation is commonly observed in patients with COPD; however, clinical parameters cannot identify such change. A resting $\mathrm{SpO}_{2}$ of $<95 \%$ has been reported to be a predictor of exercise-induced desaturation, especially in patients with a $\geq 36 \%$ reduction in DLCO ${ }^{(14)} \mathrm{Zafar}$ et al. ${ }^{(15)}$ found no significant correlation between changes (decreases) in $\mathrm{SpO}_{2}$ and resting $\mathrm{SpO}_{2}$. Our study also found no significant correlation between baseline $\mathrm{SpO}_{2}$ and decreases in $\mathrm{SpO}_{2}$ $(r=0.08 ; p=0.46)$.

The basis on which the theory of exercise intolerance in COPD is built is multifactorial: increased respiratory muscle work and oxygen uptake; lower limb skeletal muscle dysfunction; and dynamic lung hyperinflation; acting either alone or in combination. ${ }^{(8)}$ Zafar et al., ${ }^{(15)}$ studying 30 patients with COPD, reported a good correlation between oxygen desaturation during the 6MWT and dynamic hyperinflation, but no correlation with the 6MWD. Our results also showed no correlation between desaturation and the 6MWD; however, we did not assess hyperinflation in the present study.

We found that the 6MWD showed no correlation with changes in $\mathrm{SpO}_{2}$. There have been reports of skeletal muscle changes in patients with COPD, with the predominance of glycolytic fibers over oxidative fibers being highlighted. As a result, patients predominantly use the anaerobic metabolism at a low level of exercise, ${ }^{(16,17)}$ characterizing a change in the metabolic pathway and reducing the aerobic load. The occurrence of some factors, such as inflammatory stress, physical deconditioning, prolonged use of corticosteroids, and hypoxemia, contributes to altering muscle contractile activity, triggering a series of adaptations that involve muscle fiber changes. According to one group of authors, ${ }^{(18)}$ the work of breathing in the group of COPD patients who recruit abdominal muscles is twice that in the group of COPD patients who do not do so, being associated with increased dyspnea and decreased exercise tolerance. This is a possible explanation for our results, since patients may have a predominance of glycolytic fibers, may not recruit abdominal muscles, or both.

Previous studies ${ }^{(19,20)}$ have shown that the time to desaturation during the 6MWT is an indicator of the possibility of desaturation during activities of daily living, culminating in severe hypoxemia and the need for oxygen therapy. Jenkins \& Cecins ${ }^{(21)}$ analyzed the adverse events that occurred during the 6MWT in a group of 572 patients with COPD who completed the 6MWT; 345 (47\%) of the patients experienced significant desaturation ( $a \geq 4 \%$ decrease). The study by Jenkins \& Cecins $^{(21)}$ highlights the importance of continuous monitoring $\mathrm{SpO}_{2}$ during the 6MWT. The telemetry system used at the HCPA enabled us to monitor the behavior of $\mathrm{SpO}_{2}$ during the 6MWT in real time.

One group of authors ${ }^{(20)}$ showed that, of 83 patients with COPD who performed the 6MWT, 48 experienced early desaturation $\left(\mathrm{SpO}_{2}<90 \%\right.$ before the first minute) and that, over a 5-year follow-up period, $65 \%$ of those patients developed severe hypoxemia and required home oxygen therapy, compared with $11 \%$ of the patients who did not experience early desaturation $(p<$ 0.001 ). Early desaturation is also associated with desaturation during a 24-h period and during most activities of daily living. In our sample of patients who experienced desaturation during the 6MWT, we noticed that most experienced desaturation of $\geq 4 \%$ within the first minute (71\% and 63\% of the sevCOPD and modCOPD group patients, respectively), which indicates the need for a more rigorous assessment of the routine activities of these individuals.

In one study, ${ }^{(22)} 224$ patients with COPD were divided into two groups: those with and those without oxygen desaturation during the 6MWT. The patients were followed for 3 years, and the desaturation group was found to have a more rapid decline in $\operatorname{FEV}_{1}(p=0.006)$, which suggests that exercise-induced desaturation can be a predictor of pulmonary function decline in patients with COPD. In our study, FEV was found to be a good indicator of exercise-induced desaturation, showing a significant moderate negative correlation with the $\Delta \mathrm{SpO}_{2}(r=-0.398$; $\mathrm{p}<0.001)$ and time to the minimum $\mathrm{SpO}_{2}(\mathrm{r}=$ $-0.448 ; p<0.001)$.

0xygen desaturation is a monitoring parameter that qualifies the performance of patients on the 6MWT and aids in determining the degree of disease-related impairment during physical exertion. Analysis of desaturation curves allows a comprehensive view of the time to a decrease in $\mathrm{SpO}_{2}$, the intensity of that decrease, and the 
recovery time, which can assist in determining clinical severity. However, to our knowledge, no other studies have reported this type of data, which precludes a comparison with our results.

The present study underscores the importance of oxygen desaturation analysis with continuous monitoring during the 6MWT in patients with COPD. In the sevCOPD group, in comparison with the modCOPD group, $\mathrm{SpO}_{2}$ was lower and most patients experienced early desaturation (within the first minute), suggesting a worse prognosis. The FEV 1 variable was found to be a good marker of exercise-induced desaturation, showing a moderate correlation with the minimum $\mathrm{SpO}_{2}$, $\Delta \mathrm{SpO}_{2}$, and time to the minimum $\mathrm{SpO}_{2}$.

\section{References}

1. Brunetto AF, Pitta FO, Probst VS, Paulin E, Yamaguti WP, Ferreira LF. Influência da saturação de 02 na velocidade do teste de distância percorrida de seis minutos em pacientes com DPOC grave. Rev Bras Fisioter. 2003;7(2):123-9.

2. Rondelli RR, Oliveira AN, Dal Corso S, Malaguti C. Uma atualização e proposta de padronização do teste de caminhada de seis minutos. Fisioter Movimento. 2009;22(2):249-59.

3. Pires SR, Oliveira AC, Perreira VF, Britto RR. Teste de caminhada de seis minutos em diferentes faixas etárias e indice de massa corporal. Rev Bras Fisioter. 2007;11(2):14751. http://dx.doi.org/10.1590/S1413-35552007000200010

4. Ziegler B, Rovedder PM, Lukrafka JL, Oliveira CL, MennaBarreto SS, Dalcin Pde T. Submaximal exercise capacity in adolescent and adult patients with cystic fibrosis. J Bras Pneumol. 2007;33(3):263-9. http://dx.doi.org/10.1590/ S1806-37132007000300006

5. Dumke A. Estudo do comportamento da saturação periférica de oxigênio durante o teste de caminhada de 6 minutos em pacientes com doenças pulmonares crônicas [dissertation] Porto Alegre: Faculdade de Medicina da Universidade Federal do Rio Grande do Sul; 2006.

6. Rodrigues SL, Mendes HF, Viegas CA. Teste da caminhada de seis minutos: estudo do efeito do aprendizado em portadores de doença pulmonar obstrutiva crônica. J Pneumol. 2004;30(2):121-5.

7. ATS Committee on Proficiency Standards for Clinical Pulmonary Function Laboratories. ATS statement: guidelines for the six-minute walk test. Am J Respir Crit Care Med. 2002;166(1):111-7. http://dx.doi.org/10.1164/ ajrccm.166.1.at1102

8. Russo R, lamonti VC, Jardim JR. Intolerância ao exercício no paciente com DPOC. Pneumol Paulista. 2012;26(1):38-41.

9. Global Initiative for Chronic Obstructive Lung Disease [homepage on the Internet]. Bethesda: Global Initiative for Chronic Obstructive lung Disease. [cited 2013 Oct 21]. Global Strategy for the Diagnosis, Management and Prevention of Chronic Obstructive Pulmonary Disease. Updated 2013. [Adobe Acrobat document, 99p.]. Available from: http://www.goldcopd.org/uploads/users/files/ GOLD_Report_2013_Feb20.pdf
10. Sociedade Brasileira de Pneumologia e Tisiologia. Diretrizes para testes de função pulmonar. J Pneumol. 2002;28(Suppl 3):S83-S238.

11. Crapo RO, Morris AH, Gardner RM. Reference spirometric values using techniques and equipment that meet ATS recommendations. Am Rev Respir Dis. 1981;123(6):659 64.

12. Puente Maestú L, García de Pedro J. Lung function tests in clinical decision-making. Arch Bronconeumol. 2012;48(5):161-9 http://dx.doi.org/10.1016/j. arbr.2011.12.007

13. Hagarty EM, Skorodin MS, Langbein WE, Hultman $\mathrm{Cl}$, Jessen JA, Maki KC. Comparison of three oxygen delivery systems during exercise in hypoxemic patients with chronic obstructive pulmonary disease. Am J Respir Crit Care Med. 1997;155(3):893-8. http://dx.doi.org/10.1164/ ajrccm.155.3.9117023

14. Knower MT, Dunagan DP, Adair NE, Chin R Jr. Baseline oxygen saturation predicts exercise desaturation below prescription threshold in patients with chronic obstructive pulmonary disease. Arch Intern Med. 2001;161(5):732-6. http://dx.doi.org/10.1001/archinte.161.5.732

15. Zafar MA, Tsuang W, Lach L, Eschenbacher W, Panos RJ. Dynamic Hyperinflation correlates with exertional oxygen desaturation in patients with chronic obstructive pulmonary disease lung. 2013;191(2):177-82 http:// dx.doi.org/10.1007/s00408-012-9443-3

16. Gosker HR, van Mameren H, van Dijk PJ, Engelen MP, van der Vusse GJ, Wouters EF, et al. Skeletal muscle fibre-type shifting and metabolic profile in patients with chronic obstructive pulmonary disease. Eur Respir J. 2002;19(4):617-25. http://dx.doi.org/10.1183/0903 1936.02.00762001

17. Engelen MP, Schols AM, Does JD, Gosker HR, Deutz NE, Wouters EF. Exercise-induced lactate increase in relation to muscle substrates in patients with chronic obstructive pulmonary disease.. Am J Respir Crit Care Med. 2000;162(5):1697-704. http://dx.doi.org/10.1164/ ajrccm.162.5.9910066

18. Aliverty A, Macklem PT. Last Word on Point:Counterpoint: The major limitation to exercise performance in COPD is 1) inadequate energy supply to the respiratory and locomotor muscles, 2) lower limb muscle dysfunction, 3) dynamic hyperinflation. J Appl Physiol (1985). 2008;105(2):763.

19. García-Talavera 1, García CH, Macario CC, de Torres JP, Celli BR, Aguirre-Jaime A. Time to desaturation in the 6-min walking distance test predicts 24-hour oximetry in COPD patients with a P02 between 60 and 70mmHg. Respir Med. 2008;102(7):1026-32. http:// dx.doi.org/10.1016/j.rmed.2008.02.004

20. Garcia-Talavera 1, Tauroni A, Trujillo JL, Pitti R, Eiroa $\mathrm{L}$, Aguirre-Jaime A, et al. Time to desaturation less than one minute predicts the need for long-term home oxygen therapy. Respir Care. 2011;56(11):1812-7. http:// dx.doi.org/10.4187/respcare.01164

21. Jenkins S, Cecins N. Six-minute walk test: observed adverse events and oxygen desaturation in a large cohort of patients with chronic lung disease. Intern Med J. 2011;41(5):41622. http://dx.doi.org/10.1111/j.1445-5994.2010.02169.x

22. Kim C, Seo JB, Lee SM, Lee JS, Huh JW, Lee JH, et al. Exertional desaturation as a predictor of rapid lung function decline in COPD. Respiration. 2013;86(2):109-16 http://dx.doi.org/10.1159/000342891 


\section{About the authors}

\section{Maria Ângela Fontoura Moreira}

Head. Pulmonary Physiology Clinic, Department of Pulmonology, Porto Alegre Hospital de Clínicas, Porto Alegre, Brazil.

\section{Gabriel Arriola de Medeiros}

Intern. Pulmonary Physiology Clinic, Department of Pulmonology, Porto Alegre Hospital de Clínicas, Porto Alegre, Brazil.

\section{Francesco Pinto Boeno}

Intern. Pulmonary Physiology Clinic, Department of Pulmonology, Porto Alegre Hospital de Clínicas, Porto Alegre, Brazil.

\section{Paulo Roberto Stefani Sanches}

Engineer. Department of Research and Development in Biomedical Engineering, Porto Alegre Hospital de Clínicas, Porto Alegre, Brazil.

\section{Danton Pereira da Silva Júnior}

Engineer. Department of Research and Development in Biomedical Engineering, Porto Alegre Hospital de Clínicas, Porto Alegre, Brazil.

\section{André Frotta Müller}

Engineer. Department of Research and Development in Biomedical Engineering, Porto Alegre Hospital de Clínicas, Porto Alegre, Brazil. 